\title{
Evaluation of the correlation between unilateral chewing and postural deviations
}

\author{
Márcia do Amaral Sampaio', Ana Paula Lefèvre² \\ Escola Nacional de Saúde Integrada, São Paulo, SP, Brazil \\ ${ }^{1}$ Corresponding author \\ E-mail: ${ }^{1}$ cehasampaio@hotmail.com, ${ }^{2}$ analefevre@ensi.com.br
}

Received 15 May 2021; received in revised form 24 July 2021; accepted 23 August 2021 DOI https://doi.org/10.21595/ffocg.2021.22062

Check for updates

Copyright $\odot 2021$ Márcia do Amaral Sampaio, et al. This is an open access article distributed under the Creative Commons Attribution License, which permits unrestricted use, distribution, and reproduction in any medium, provided the original work is properly cited.

\begin{abstract}
The objective of this study is to describe the head posture and postural deviations in individuals with unilateral chewing. The sample was composed of 31 individuals of both sexes aged between 7 and 17 years old, who presented median line deviation and predominant unilateral mastication. The evaluation was made by three professionals (a speech therapist, a physiotherapist and a dentist) through a postural exam, where the patient is placed on a symmetrograph in an erect position: the head in position of repose, eyes fixed on the horizon, arms along the body, and feet physiologically positioned. Each patient was analyzed under frontal, sagittal, and lateral planes, in search for an eventual lateral deviation of the spine. Additionally, the posture was analyzed in photographs and videos, where body movement was recorded. After clinical analyses, a segmenting radiographic study of the spinal column was conducted. Results showed a high prevalence of head rotation towards the chewing side and lateral flexion towards the opposite side. Also, forward head posture (anteroposition) and scoliotic attitude were found. The X-rays confirmed a high prevalence of scoliosis with no association to the chewing side. The data suggest that children and adolescents with unilateral mastication present some postural deviation.
\end{abstract}

Keywords: unilateral mastication, postural deviations.

\section{Introduction}

The influence of stomatognathic function on body posture was first introduced by Pierre Robin in 1902 [1] when he described the Glossoptosis Syndrome, characterized by symptoms including headaches, scapular waist's deviations, and even flat feet. Other authors investigated the relationship between occlusion and posture, starting with Dart (1946) [2] and Solow and Tallgren (1976) [3].

With evolution, the primordial changes that occurred in human morphophysiology were the horizontal flattening of the skull and a decrease in prognathism and facial divergences [4]. The Stomatognathic System (SS) is set in motion during the act of chewing that ideally occurs bilaterally and alternately [5-7]. Dry, hard, and fibrous foods cause important stimuli for the development of the SS during masticatory training, generating neural stimuli and developmental responses $[6,8]$.

Unilateral mastication can cause a unilateral posterior crossbite, which is a broad asymmetric malocclusion characterized by an inverse relationship between the upper and lower vestibular dental cusps in the molar and premolar regions on one side of the dental arch. Patients with unilateral posterior crossbite have altered masticatory cycles and the crossbite-side masseter is less active compared to the contralateral one [9]. Studies have related the presence of this sort of asymmetry to occlusal interference, abnormal mandible growth, and asymmetric muscle activity $[10,11]$. However, other studies have reported that crossbite does not contribute to asymmetric muscle activity during functional tasks [12], nor to a preferred side of chewing [13, 14].

Unilateral chewing may be associated with body posture, especially postural control and scoliosis $[15,16]$, although no association has been shown between the scoliosis side and the posterior crossbite side [15]. The sensory information received by the vestibular, visual, and 
proprioceptive systems modulates postural balance [17]. It has been reported that temporarily manipulated occlusion in different mandibular positions or sitting/standing positions may result in different body postures [18].

If the spine is subjected to different pressures for a prolonged period, it may affect the vertebral bodies and tends to generate deformities [19]. The part of the bone submitted to higher pressure grows less than the part under lower pressure, determining the concave and convex side of scoliosis. According to Bricot [20], there is high prevalence of scoliosis after dental malocclusions treatments.

Considering the laws of growth and development of the SS [7], this study aims to analyze the correlation between preferential chewing side and mandibular deviation, and describe the postural deviations, especially in the frontal plane, and the head position present in individuals with unilateral chewing.

\section{Methods}

The present descriptive exploratory study included 31 individuals with midline deviation (Fig. 1) and unilateral chewing, who sought care at the Clinical School of the Functional Orthopedics in Holistic Dentistry course of the Faculty of Health Sciences. They had not received previous speech therapy, physical therapy, orthodontic or functional orthopedic treatment of the jaws. Those with severe temporomandibular joint (TMJ) disorders or spontaneous painful symptoms, absence of teeth, any type of syndrome or systemic pathology, and history of trauma in the head or spine regions were excluded. Parents and guardians signed an informed consent form and all subjects were subsequently treated in the clinic by a team consisting of physiotherapists, speech therapists and dentists.

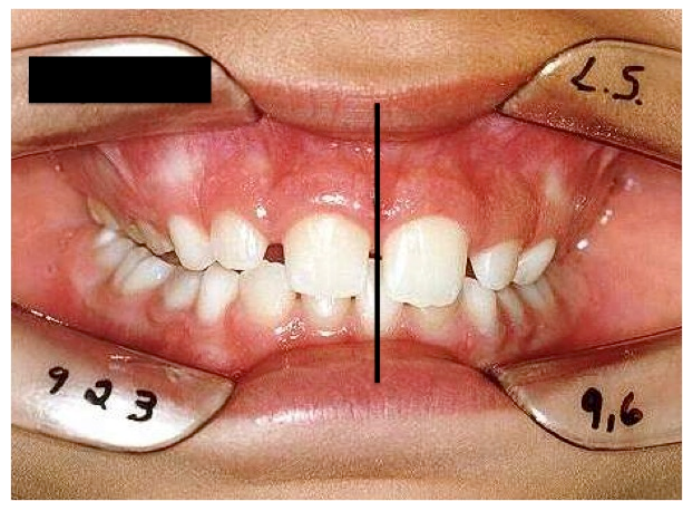

Fig. 1. Midline deviation

Static and dynamic evaluations of the SS and the body posture of the subjects in the sample were carried out. The evaluation of the SS included morphological and functional aspects, especially mastication. A multidisciplinary team, consisting of a dentist, a speech therapist, and a physiotherapist, performed postural analysis.

To assess the SS, an instrument developed in the institution was used. This form contains data related to structural aspects, description of the malocclusion, presence or absence of pain, chewing side, presence of mandibular deviation, muscle condition and asymmetries [21]. Cheese bread (of constant brand and size) was chosen to assess masticatory function due to acceptance, texture, consistency, size and flavor. The dynamic recording was obtained with a Sony 200X Digital camcorder. The video was used to confirm the chewing side and to compare the results of static postural analyses.

Global postural assessment was performed in three different ways using an instrument developed for institutional use: by muscle chains analysis [20, 22], by evaluation of the static 
posture, and analysis in photographs (Fig. 2).

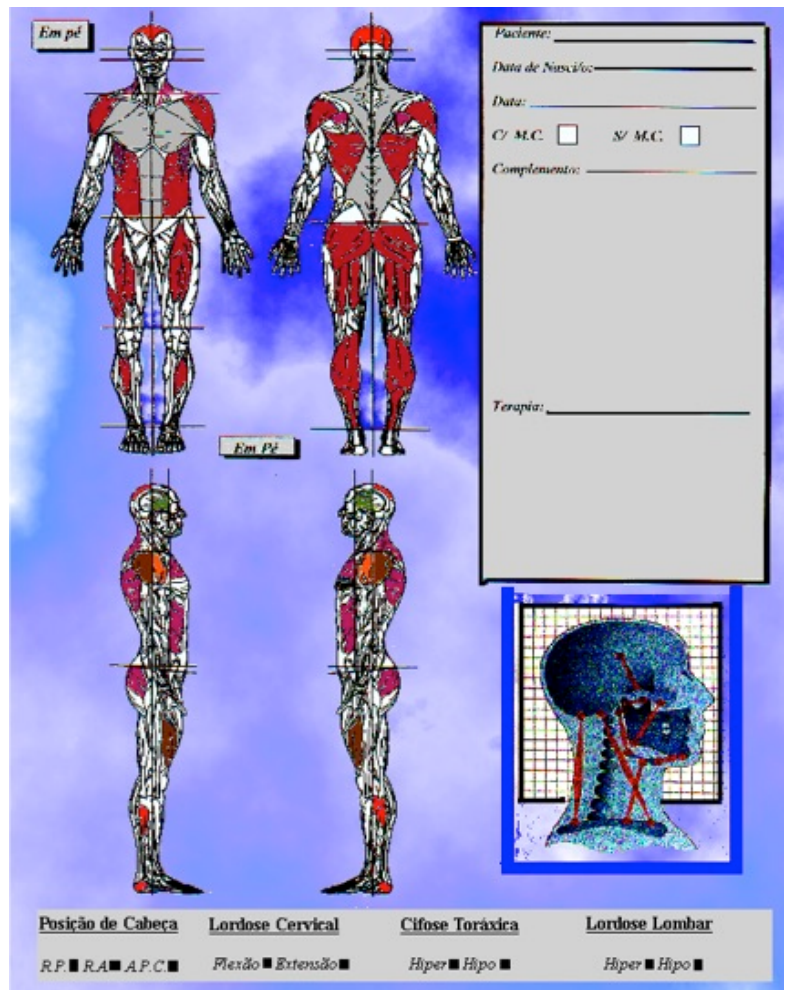

Fig. 2. Instrument of global postural assessment

The photos were taken with the individuals standing, positioned in a standard-sized symmetrograph (98 cm wide by $286 \mathrm{~cm}$ high) with an exchangeable and adjustable footrest as standard, without any support, feet arranged in $\mathrm{V}$, and adjusted in the demarcation in frontal, dorsal and lateral (right and left) views. They were observed at the same distance, place, and position. They were wearing light clothes (swimwear, bikini), barefoot, eyes open (looking in parallel to the ground), behind a grid panel measuring $95 \mathrm{~mm}$ of edge. A Pentax Zoom 90-WR camera was rotated and locked 90 degrees from the horizontal position (longitudinal to the body) and positioned at a distance of 2.60 meters from the panel on a tripod (90 cm height) regulated for each patient so that the focus of the photographic lens was centered on the region of the navel of the subject in the frontal view. All horizontal planes were leveled with a bubble level. The photos were printed in size $10 \times 15 \mathrm{~cm}$ and used to confirm the postural evaluation.

Five radiographic segmented images of the cervical, dorsal, and lumbar spine were performed in the orthostatic position: in the lateral view for the cervical and thoracolumbar spine, and frontal view (anteroposterior, AP) for the cervical, dorsal and lumbar spine. The technical procedures and recordings were conducted according to the INRAD (Radiology Institute of the Hospital das Clínicas of the Faculty of Medicine of the University of São Paulo) standards: the individuals had their median sagittal plane parallel to the horizontal ceiling stand, barefoot, feet together, in their usual orthostatic body posture, and looking at the horizon. To control bias, three different physiotherapists performed the interpretation of radiography. The results were compared and only the coincident in the three analyses were considered.

The data obtained were compared and statistical analysis was performed with the Spearman's Correlation, significance level $5 \%$. The Statistical Packet for Social Science (SPSS, version 10.0) software was used. 


\section{Results}

The sample was composed by 31 children and adolescents of both sexes, being $54.84 \%$ female $(n=17)$ and $45.16 \%$ male $(n=14)$, aged between 7 and 17 years, with a mean age of 11 years. A higher frequency of preferably chewing on the right $(n=21)$ than on the left side $(n=10)$ was found. No significant associations were found regarding age, gender, or lateral dominance.

The side of the midline deviation was coincident with the chewing side in most subjects ( $n=30$; $96.77 \%$; $95 \%$ CI: $83.29 \%$ to $99.91 \%$ ).

When analyzing the head position, it was observed that $93.54 \%(n=29 ; 95 \% \mathrm{CI}: 78.58 \%$ to $99.20 \%$ ) of the sample presented some deviations in the frontal view, isolated or combined. Lateral head flexion were found in 26 individuals $(83.87 \%$; $95 \% \mathrm{CI}$ : $66.27 \%$ to $94.55 \%$ ), being 9 (29.03\%; $95 \%$ CI: $14.22 \%$ to $48.03 \%)$ flexed to the same side of chewing and $17(54.84 \%$; $95 \%$ CI: $36.03 \%$ to $72.68 \%$ ) flexed to the opposite side. Head rotation was observed in 23 individuals $(74.19 \%)$. A positive correlation was found between head rotation and chewing side regardless of the side. That is, unilateral chewing on the right is associated with the presence of head rotation to the same side $(r=0.788)$. The same occurs in the case of unilateral chewing on the left $(r=0.557)$.

The co-occurrence of flexion and rotation was observed in 19 individuals. The lateral flexion to the side of mastication (ipsilateral) was associated to a contralateral rotation. If there is a contralateral flexion, contralateral rotation does not occur.

In the lateral view, there was a high prevalence $(87.10 \%)$ of anteroposition of the head (forward head posture) in individuals with unilateral mastication $(n=27 ; 95 \% \mathrm{CI}: 70.16 \%$ to $96.37 \%$ ) (Fig. 3).

The postural global assessment showed in the frontal view 24 (77.42\%) individuals with convexity, usually called scoliotic attitudes (Fig. 4). From those, 22 individuals presented convexity in the dorsal or lumbar regions and two presented both. Radiographic examinations, in addition to confirming the postural analyses, showed three more individuals with deviations totaling $27(87.10 \%)$ with some type of scoliosis (cervical-dorsal, dorsal, dorsal-lumbar or lumbar), with varying degrees of severity. There was no correlation between the preferred chewing side and the convexity side of the spinal segments (confirmed by x-ray). A correlation between lateral head flexion and dorsal-lumbar convexity was observed to the same side.

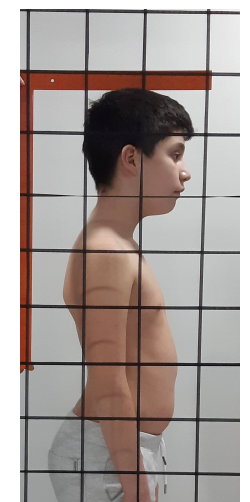

Fig. 3. Forward head posture

The convexity observed in the photos and in the postural analyses (sagittal view) were compatible with scoliosis found on radiography (Fig 5). The same occurred when comparing photos and the postural analysis made by the three professionals for deviations in the frontal view. 

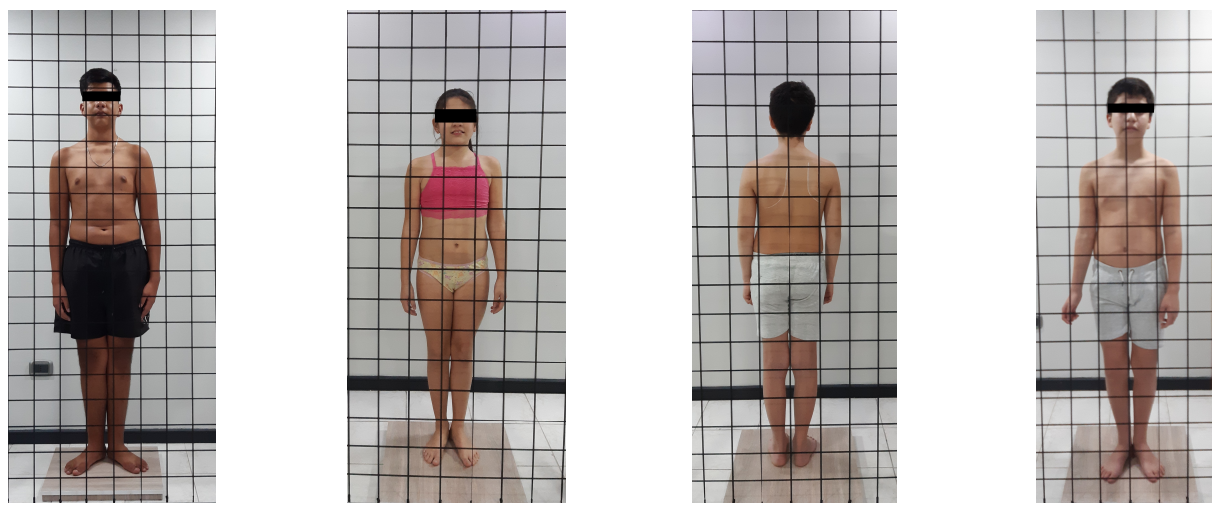

Fig. 4. Deviations in frontal view

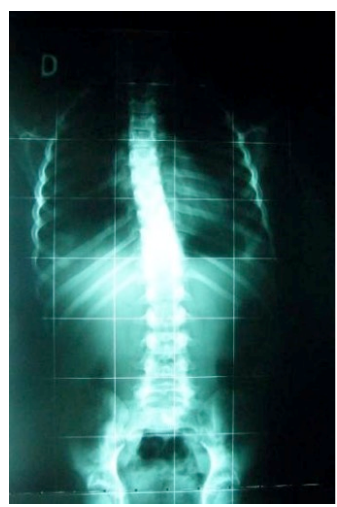

Fig. 5. Scoliosis

\section{Discussion}

Previous studies sustain that changes in body posture could interfere with mandibular positioning $[23,24]$ and suggest the sensory-motor system of the mandible can modulate postural control mechanisms [23]. Studies generally analyze free mandible movements and not functional ones [25]. Some are conducted during masticatory function and analyze mandibular and head movements only in the sagittal plane [26]. The present study analyzed functional movements in the frontal and sagittal planes. In lateral view (sagittal plane), a high prevalence of cervical spine rectification and anteroposition of the head was found.

Similar findings to the present study were seen in samples of individuals with or without symptoms of temporal-mandibular and/or cervical dysfunction and force unilateral mastication $[24,27]$. Some studies induced healthy subjects to an unbalanced occlusion using cotton rolls or silicone unilaterally, which caused a detectable change in the distribution of pressure on feet surface while walking [28, 29].

Controversial results have been reported on possible correlations between the SS and body posture $[17,30]$. A meta-analysis determined to be possible to detect a correlation between the masticatory system and postural muscle activity by electromyography [31] while another study [32] showed significant correlation between the Clarke angle (foot posture) and dental malocclusion.

The reliability of the photographic method to assess posture was demonstrated in children between 10 and 13 years of age [33] and in young adults with and without unilateral posterior crossbite [34]. In addition to evaluation by photos, the present study used dynamic recordings in video. Head movements accompany voluntary rapid mandibular movements, and the activity of 
the sternocleidomastoid and mandible precedes the activity of the head [35].

In this sample there was predominance of rotation of the head to the work side and tilting to the opposite side. Neuromuscular interactions between mandible tightening and neck muscle activity were found in studies [36]. It is possible that the association of the two head movements to the same side reduces the space between the sternocleidomastoid and jaw, making chewing difficult.

In previous studies, an important relationship between lateral head tilt and unilateral chewing was found [21], which was corroborated in the examined individuals. However, it was observed that there was no relationship pattern between the sides as in other studies [34].

Considering the muscle chains [22], the descending deviations [37], and the theory of captors [20], unilateral chewing can be seen as a parafunctional habit (captor) that unbalances the SS, taking this imbalance to other sectors of the whole organism.

This study demonstrated an association between lateral deviations and unilateral mastication without a correlation with the side. Unilateral posterior crossbite was associated with static body posture, but the side of the crossbite is not related to the direction of the effect on static body posture [34]. The relationship between craniocervical orientation and occlusion force was showed in adults [38]. The use of a functional device for the treatment of scoliosis induced a significant reduction in the index of asymmetry of trunk muscles, as well as a significant increase in the contractility of the masticatory muscles [39].

Epidemiological studies estimate the prevalence of scoliosis between $2.0 \%$ and $4.0 \%$ in children under $16[40,41]$. In the present study, children with unilateral chewing had a much higher prevalence. The deviations observed in postural analysis are named scoliotic attitudes ( $96.77 \%$ of the sample). When confirmed by radiographic examinations, scoliosis can be considered if any vertebra is rotated, as occurred in $87.10 \%$ of the sample.

An important finding was a correspondence between the chewing side and the deviation of the mandibular midline in almost all individuals, which corroborates the statements of Planas [7].

\section{Conclusions}

In unilateral mastication cases, the preferred side of work occurs on the same side as the midline deviation. The assessment of the midline could be a good way to identify alterations in the masticatory function, and, when a deviation is found, this may be indicative of unilateral mastication.

Children and adolescents up to 17 years old with unilateral chewing present some postural deviations, with anteroposition of the head and frequent scoliosis. The high prevalence of scoliosis in various degrees and segments may be indicative of the relationship between posture and the SS, which needs to be further investigated with more in-depth studies and a control group.

\section{References}

[1] P. Robin, "Demonstration pratique sur la construction et la mise en bouche d'un nouvel appareil de redressement," Revue de Stomatologie, Vol. 9, No. 3, pp. 561-90, 1902.

[2] R. A. Dart, "The postural aspect of malocclusion," Journal of the Dental Association of South Africa, Vol. 1, pp. 1-21, 1946.

[3] B. Solow and A. Tallgren, "Head posture and craniofacial morphology," American Journal of Physical Anthropology, Vol. 44, No. 3, pp. 417-435, May 1976, https://doi.org/10.1002/ajpa.1330440306

[4] M. Clauzade, Orthoposturodontie 2. 1st ed., Perpignan, France: Seoo Editions, 2007.

[5] C. R. Douglas, Tratado de Fisiologia Aplicada à Saúde. 5th ed., São Paulo: Robe Editorial, 2002.

[6] W. A. Simões, Ortopedia Funcional de los Maxilares: Vista através de la Reabilitacion Neuro-Oclusal. 1st ed., Caracas: Isaro, 2003.

[7] P. Planas, Reabilitação Neuro-Oclusal. 1st ed., São Paulo: Medsi, 1988.

[8] A. P. Lefèvre M., N. M. Costa, and S. Vieira, "Fonoaudiologia e Nutrição: A Importância da Textura dos Alimentos," Revista da Sociedade Brasileira de Fonoaudiologia, Vol. 5, No. 7, pp. 48-53, 2000. 
[9] M. G. Piancino, A. Tortarolo, A. Polimeni, E. Bramanti, and P. Bramanti, "Altered mastication adversely impacts morpho-functional features of the hippocampus: A systematic review on animal studies in three different experimental conditions involving the masticatory function," PLOS ONE, Vol. 15, No. 8, p. e0237872, Aug. 2020, https://doi.org/10.1371/journal.pone.0237872

[10] Q. Nie, Z. Kanno, T. Xu, J. Lin, and K. Soma, "Clinical study of frontal chewing patterns in various crossbite malocclusions," American Journal of Orthodontics and Dentofacial Orthopedics, Vol. 138, No. 3, pp. 323-329, Sep. 2010, https://doi.org/10.1016/j.ajodo.2008.10.020

[11] J. A. Alarcón, C. Martín, and J. C. Palma, "Effect of unilateral posterior crossbite on the electromyographic activity of human masticatory muscles," American Journal of Orthodontics and Dentofacial Orthopedics, Vol. 118, No. 3, pp. 328-334, Sep. 2000, https://doi.org/10.1067/mod.2000.103252

[12] A. Michelotti et al., "Postural stability and unilateral posterior crossbite: Is there a relationship?," Neuroscience Letters, Vol. 392, No. 1-2, pp. 140-144, Jan. 2006, https://doi.org/10.1016/j.neulet.2005.09.008

[13] C. Martín, J. A. Alarcón, and J. C. Palma, "Kinesiographic study of the mandible in young patients with unilateral posterior crossbite," American Journal of Orthodontics and Dentofacial Orthopedics, Vol. 118, No. 5, pp. 541-548, Nov. 2000, https://doi.org/10.1067/mod.2000.109494

[14] J. Martinez-Gomis, M. Lujan-Climent, S. Palau, J. Bizar, J. Salsench, and M. Peraire, "Relationship between chewing side preference and handedness and lateral asymmetry of peripheral factors," Archives of Oral Biology, Vol. 54, No. 2, pp. 101-107, Feb. 2009, https://doi.org/10.1016/j.archoralbio.2008.09.006

[15] Y. Ben-Bassat, M. Yitschaky, L. Kaplan, and I. Brin, "Occlusal patterns in patients with idiopathic scoliosis," American Journal of Orthodontics and Dentofacial Orthopedics, Vol. 130, No. 5, pp. 629633, Nov. 2006, https://doi.org/10.1016/j.ajodo.2005.01.032

[16] S. Julià-Sánchez, J. Álvarez-Herms, H. Gatterer, M. Burtscher, T. Pagès, and G. Viscor, "Dental occlusion influences the standing balance on an unstable platform," Motor Control, Vol. 19, No. 4, pp. 341-354, Oct. 2015, https://doi.org/10.1123/mc.2014-0018

[17] A. Baldini, A. Nota, D. Tripodi, S. Longoni, and P. Cozza, "Evaluation of the correlation between dental occlusion and posture using a force platform," Clinics, Vol. 68, No. 1, pp. 45-49, Jan. 2013, https://doi.org/10.6061/clinics/2013(01)oa07

[18] B. Scharnweber et al., "Influence of dental occlusion on postural control and plantar pressure distribution,” CRANIO ${ }^{\circledR}$, Vol. 35, No. 6, pp. 358-366, Nov. 2017, https://doi.org/10.1080/08869634.2016.1244971

[19] L. M. Silva Filho, Fisioterapia da Escoliose Idiopática. 1st ed., Rio de Janeiro: Editora de Publicações Biomédicas, 2000.

[20] B. Bricot, Posturologia. 2nd. ed., São Paulo: Ícone, 2010.

[21] M. A. Sampaio, "Desvios Posturais Relacionados com as Má-Oclusões Dentárias," Terapia Manual, Vol. 1, No. 2, pp. 29-31, 2002.

[22] A. P. Marques, Cadeias Musculares: Um Programa para Ensinar Avaliação Fisioterapêutica Global. 1st ed., São Paulo: Manole, 2000.

[23] A. Alghadir, H. Zafar, S. L. Whitney, and Z. Iqbal, "Effect of chewing on postural stability during quiet standing in healthy young males," Somatosensory and Motor Research, Vol. 32, No. 2, pp. 72-76, Apr. 2015, https://doi.org/10.3109/08990220.2014.969837

[24] A. M. Cuccia, "Interrelationships between dental occlusion and plantar arch," Journal of Bodywork and Movement Therapies, Vol. 15, No. 2, pp. 242-250, Apr. 2011, https://doi.org/10.1016/j.jbmt.2010.10.007

[25] S. Kohno, T. Matsuyama, R. U. Medina, and Y. Arai, "Functional-rhythmical coupling of head and mandibular movements," Journal of Oral Rehabilitation, Vol. 28, No. 2, pp. 161-167, Feb. 2001, https://doi.org/10.1046/j.1365-2842.2001.00636.x

[26] P.-O. Eriksson, B. Häggman-Henrikson, E. Nordh, and H. Zafar, "Co-ordinated mandibular and headneck movements during rhythmic jaw activities in man," Journal of Dental Research, Vol. 79, No. 6, pp. 1378-1384, Jun. 2000, https://doi.org/10.1177/00220345000790060501

[27] J. Huggare, "Postural disorders and dentofacial morphology," Acta Odontologica Scandinavica, Vol. 56, No. 6, pp. 383-386, Jan. 1998, https://doi.org/10.1080/000163598428374

[28] S. Tecco, A. Polimeni, M. Saccucci, and F. Festa, "Postural loads during walking after an imbalance of occlusion created with unilateral cotton rolls," BMC Research Notes, Vol. 3, No. 1, pp. 141-141, Dec. 2010, https://doi.org/10.1186/1756-0500-3-141 
[29] D. Ohlendorf, K. Seebach, S. Hoerzer, S. Nigg, and S. Kopp, "The effects of a temporarily manipulated dental occlusion on the position of the spine: A comparison during standing and walking," The Spine Journal, Vol. 14, No. 10, pp. 2384-2391, Oct. 2014, https://doi.org/10.1016/j.spinee.2014.01.045

[30] Clinics, "ERRATA," Clinics, Vol. 67, No. 9, pp. 1123-1123, Sep. 2012, https://doi.org/10.6061/clinics/2012(09)22

[31] A. Baldini, G. Cravino, and A. Rinaldi, "Gnathological postural analysis and treatment in air force pilots: a case report," Mondo Ortodontico, Vol. 36, pp. 208-215.

[32] A. Marchena-Rodríguez, N. Moreno-Morales, E. Ramírez-Parga, M. T. Labajo-Manzanares, A. LuqueSuárez, and G. Gijon-Nogueron, "Relationship between foot posture and dental malocclusions in children aged 6 to 9 years," Medicine, Vol. 97, No. 19, p. e0701, May 2018, https://doi.org/10.1097/md.0000000000010701

[33] J. Paušić, Pedišić, and D. Dizdar, "Reliability of a photographic method for assessing standing posture of elementary school students," Journal of Manipulative and Physiological Therapeutics, Vol. 33, No. 6, pp. 425-431, Jul. 2010, https://doi.org/10.1016/j.jmpt.2010.06.002

[34] J. Zurita-Hernandez, R. Ayuso-Montero, M. Cuartero-Balana, E. Willaert, and J. Martinez-Gomis, "Relationship between unilateral posterior crossbite and human static body posture," International Journal of Environmental Research and Public Health, Vol. 17, No. 15, p. 5303, Jul. 2020, https://doi.org/10.3390/ijerph17155303

[35] T. Torisu, Y. Yamabe, N. Hashimoto, T. Yoshimatsu, and H. Fujii, "Head movement properties during voluntary rapid jaw movement in humans," Journal of Oral Rehabilitation, Vol. 28, No. 12, pp. 1144-1152, Dec. 2001, https://doi.org/10.1046/j.1365-2842.2001.00782.x

[36] N. N. Giannakopoulos, D. Hellmann, M. Schmitter, B. Krüger, T. Hauser, and H. J. Schindler, "Neuromuscular interaction of jaw and neck muscles during jaw clenching," Journal of Orofacial Pain, Vol. 27, No. 1, pp. 61-71, 2013, https://doi.org/10.11607/jop.915

[37] M. Bienfait, Os Desequilíbrios Estáticos. 1st ed., São Paulo: Summus, 1995.

[38] C. D. Westersund, J. Scholten, and R. J. Turner, "Relationship between craniocervical orientation and center of force of occlusion in adults," $C R A N I O{ }^{\circledR}$, Vol. 35, No. 5, pp. 283-289, Sep. 2017, https://doi.org/10.1080/08869634.2016.1235254

[39] S. Tecco et al., "SEMG activity of masticatory, neck, and trunk muscles during the treatment of scoliosis with functional braces. A longitudinal controlled study," Journal of Electromyography and Kinesiology, Vol. 21, No. 6, pp. 885-892, Dec. 2011, https://doi.org/10.1016/j.jelekin.2011.08.004

[40] H. Y lmaz, C. Zateri, A. Kusvuran Ozkan, G. Kayalar, and H. Berk, "Prevalence of adolescent idiopathic scoliosis in Turkey: an epidemiological study," The Spine Journal, Vol. 20, No. 6, pp. 947-955, Jun. 2020, https://doi.org/10.1016/j.spinee.2020.01.008

[41] Dantas Milla Gabriela Belarmino, "Prevalência de escoliose idiopática e de dor nas costas em crianças e adolescentes do sertão de Pernambuco," Ph.D. Thesis, Universidade de Sao Paulo, Agencia USP de Gestao da Informacao Academica (AGUIA), 2020.

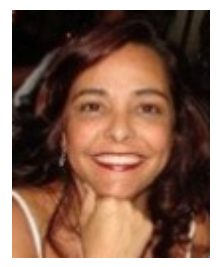

Márcia do Amaral Sampaio received master's degree in Movement Science and from Guarulhos University, Guarulhos, Brazil, in 2003, and is specialty in Maxillary Orthopedic. Now, she works at Escola Nacional de Saúde Integrada.

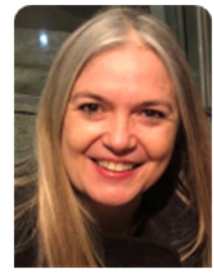

Ana Paula Lefèvre received Ph.D. degree in Public Health from School of Medical Sciences, Santa Casa, São Paulo, Brazil, in 2019, and is specialty in Maxillary Ortopedic. Now, she works at Escola Nacional de Saúde Integrada. 